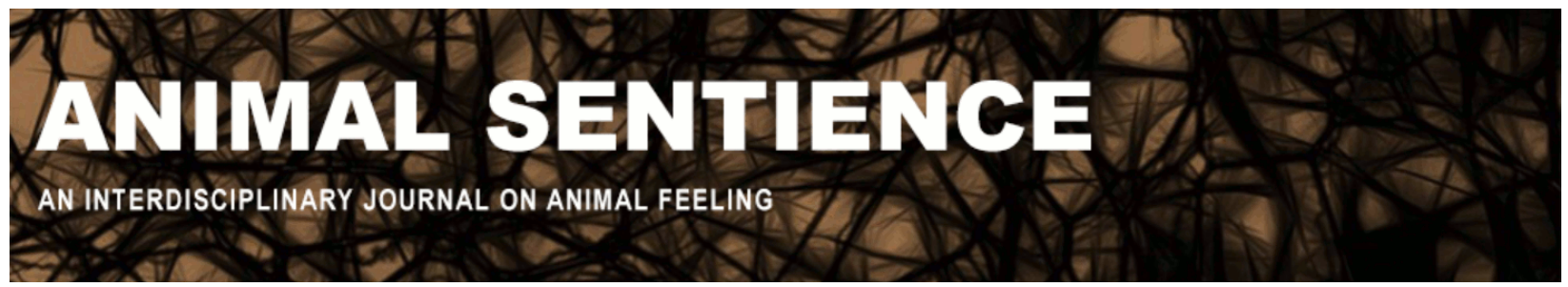

Bräuer, Juliane and Amici, Federica (2018) Fake or not: Two prerequisites for jealousy. Animal Sentience 22(18)

DOI: $10.51291 / 2377-7478.1354$

Date of submission: 2018-06-26

Date of acceptance: 2018-07-12

(c)

This article has appeared in the journal Animal

Sentience, a peer-reviewed journal on animal

cognition and feeling. It has been made open access,

free for all, by WellBeing International and deposited

in the WBI Studies Repository. For more information,

please contact

wbisr-info@wellbeingintl.org.

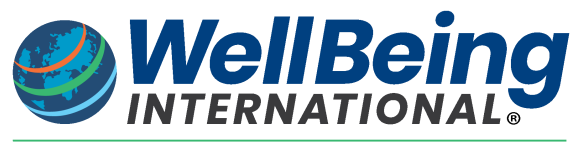

SOLUTIONS FOR PEOPLE, ANIMALS AND ENVIRONMENT 


\title{
Fake or not: Two prerequisites for jealousy
}

\author{
Commentary on Cook et al. on Dog Jealousy
}

\author{
Juliane Bräuer ${ }^{1,2}$ and Federica Amici ${ }^{3,4}$ \\ ${ }^{1}$ Max-Planck-Institute for the Science of Human History, Jena, Germany \\ ${ }^{2}$ Department of General Psychology and Cognitive Neuroscience, FSU, Jena, Germany \\ ${ }^{3}$ Max Planck Institute for Evolutionary Anthropology, Leipzig, Germany \\ ${ }^{4}$ University of Leipzig Faculty of Life Science, Institute of Biology, Leipzig, Germany
}

\begin{abstract}
Cook and colleagues (2018) use a novel approach to test jealousy in dogs. Although such a non-invasive approach is more than welcome in comparative research, several methodological shortcomings limit the impact of this study. We briefly outline two main problems. (1) There is no evidence that the fake dogs in the study were perceived as real, and thus as social rivals, which would be a prerequisite for jealousy. (2) It is questionable whether dogs generally show the cognitive prerequisites for jealousy, such as attentiveness toward a social rival, the ability to understand intentions, and a sense of fairness. We suggest that future studies should combine the same creativity with more controlled procedures in order to better understand the evolutionary origins of jealousy.
\end{abstract}

Juliane Bräuer is a researcher at the MaxPlanck-Institute for the Science of Human History and the University of Jena. Her research is in Comparative Psychology with a special interest in investigating the cognitive skills that different species - particularly dogs - have evolved to survive in their ecological niche. Her research topics include communication, cooperation, perception and individual differences. Website

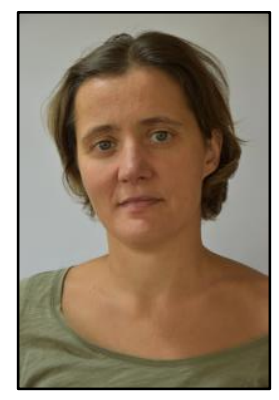

Federica Amici is a post-doctoral researcher at the University of Leipzig and the Max Planck Institute for Evolutionary Anthropology, where she is especially interested in the evolutionary forces shaping the distribution of cognitive skills across vertebrates, to better understand the relative contribution of social and ecological factors to the evolution of complex cognitive

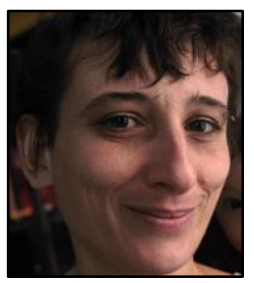
skills. Website

“I didn't mean to hurt you ... I am just a jealous guy." John Lennon (1971)

As jealousy plays a major role in our everyday life, it inspires not only songwriters and other artists but also researchers in comparative cognition. The huge interest in this topic is illustrated by the numerous commentaries on Cook, Prichard, Spivak and Berns's (2018) target article on jealousy in dogs. The authors have the huge merit of exploring jealousy in dogs by using non-invasive brain imaging (fMRI). At a historic moment when interest in replacing, reducing and refining the use of animals for scientific purposes (Directive 2010/63/EU) is at 
last growing, this study is an important first step toward a more ethical and scientifically sound approach to the study of animal behavior and cognition (see Singer, 2018).

As a first step, it is no wonder that this approach also has several methodological limits, as other researchers have extensively noted in their commentaries. For example, is it correct to talk about jealousy, instead of, say, inequity aversion, when the dog reacts negatively to the loss of a valuable resource - in particular when the dog has no close relationship to the experimenter (Harmon-Jones \& Harmon-Jones, 2018; Vonk, 2018)? Is there really a relationship between dog-directed aggression and amygdala activation (Denson, 2018; Silver \& Santos, 2018) in view of the fact that no dog in the study actually showed aggression (Walsh, 2018)? Could the fact that the dogs in the study reacted differently when the food disappeared into the bucket (compared to when it was delivered to the fake dog) simply be because it was perceived as still being available (Serpell, 2018; Vonk, 2018; Zentall, 2018)? And finally: was the fake dog really perceived as a conspecific (Vonk, 2018)?

In our opinion, the last issue is especially problematic: perceiving the fake dog as a real conspecific is indeed a necessary prerequisite to talk about jealousy. All three studies that have so far experimentally tested jealousy in dogs, used fake dogs (Cook et al., 2018; Harris \& Prouvost, 2014; Prato-Provide et al., 2018), but none of these studies actually provided evidence that the fake dogs were perceived as real - and thus, as social rivals.

Indeed, it is quite unlikely that dogs - with their social sensitivity and their excellent sense of smell - perceive a fake dog as a real one. Several studies show that dogs distinguish between fake (or unnatural) and real situations. Macpherson and Roberts (2006) tested whether dogs seek help in an emergency situation. Dogs' owners feigned a heart attack. Although dogs could ask for help from a human bystander, none of the dogs solicited help. Possibly, thanks to their excellent sense of smell, dogs in this study did not perceive the situation as an emergency case, simply because the emergency was not real (Bräuer, 2015). Indeed, there is growing evidence that dogs alert to real epilepsy and diabetes seizures, and might even be able to predict them, even when they were not trained to do so (i.e., Dalziel et al., 2003; Lim et al., 1992). Similarly, Bräuer et al. (2013) tested whether dogs would open a door for a human, so that she could enter a target room and retrieve a key. Dogs did not help when the human showed a predetermined series of actions (e.g., gaze alternation between the key and dog; reaching for the key; shaking the door) to show what she wanted. However, when the human interacted with the dog, combining these actions in a more spontaneous, unscripted way, the dogs were much more likely to provide help. Finally, in a habituationdishabituation paradigm, dogs could distinguish between an animate and inanimate agent interacting with an object, attributing intentions only to the animate object (Marshall-Pescini et al., 2014). All these findings suggest that dogs are extremely sensitive in distinguishing real and simulated situations, and probably fail to perceive a fake dog as a real one.

Another major question is whether dogs show the cognitive prerequisites for jealousy. Cook and colleagues (2018) define jealousy as a "set of negative emotional and behavioral responses when a rival receives something one wants for oneself". In this respect, although they probably do not require a full-blown theory of mind (Tangney \& Salovey, 1999), to show jealousy in dogs would still require attentiveness to a social rival, the ability to understand intentions and maybe even a sense of fairness (see Bräuer \& Hanus, 2012, for a review).

There is no doubt that dogs are extremely attentive toward humans (see Bräuer, 2014, for a review) and use social referencing (Merola et al., 2011, 2012). For example, dogs are able to determine when human communication is intended for them and react perfectly to ostensive cues directed to them (Kaminski et al., 2012). They may even show some limited 
form of inequity aversion, paying attention to the food received by a rival dog and reacting negatively when they themselves receive no food reward for the same action (Range et al., 2009). Similarly, dogs avoid their rival and the experimenter more during the free interaction time following unequal compared to equal treatment, although the heart rate does not differ across conditions (Brucks et al., 2016). Nietzschner and colleagues (2012), however, found that dogs evaluate humans on the basis of direct experience only. In their experiment, dogs observed a "nice" or "ignoring" human interacting with another dog but failed to establish a preference between the two humans based on this indirect experience only. Moreover, dogs have great difficulties in understanding humans' goals and intentions (Petter et al., 2009; Kaminski et al., 2011; see Bräuer, 2014, for a review).

Thus, based on these results, it is questionable whether dogs are really able to understand when rivals receive something positive (be it food or attention) or even whether they actually perceive to whom the human's actions are directed (Prato-Provide et al., 2018; Serpell, 2018; Vonk, 2018; Zentall, 2018). It is therefore unlikely that dogs in these studies really interpreted the human's behavior (praising or feeding the fake dog) as goal-directed. And even if dogs could have at least partially understood that this behavior was directed toward the rival, it is highly unlikely that the fake dog was perceived as a real rival.

Overall, this study is a promising first approach to the study of jealousy in animals. Many of the methodological limits can certainly be addressed in the future to come up with better, non-invasive procedures for the study of animal cognition. For example, it will be interesting to use this novel approach to investigate, under more controlled conditions, which species really show jealousy. Has jealousy been selected for only in domesticated animals or rather more generally in species forming strong social bonds with a few other individuals? Is jealousy only present in monogamous species, or is it, after all, something uniquely human? Further creativity and methodological rigor will surely allow us to answer these questions in the not too distant future.

\section{References}

Bräuer, J. (2014) What dogs understand about others. In Kaminski, J., \& Mashall-Pescini, S. (Eds.), The social dog: Behaviour and cognition. Elsevier Publishers.

Bräuer, J. (2015) I do not understand but I care: The prosocial dog. Interaction Studies, 16: 341-360

Bräuer, J., \& Hanus, D. (2012) Fairness in non-human primates? Social Justice Research, 25: 256-276

Bräuer, J., Schoenefeld, K., \& Call, J. (2013) When do dogs help humans? Applied Animal Behaviour Science, 148: 138-149

Brucks, D., Essler, J. L., Marshall-Pescini, S., \& Range, F. (2016) Inequity aversion negatively affects tolerance and contact-seeking behaviours towards partner and experimenter. PLOS ONE, 11(4): e0153799

Cook, P., Prichard, A., Spivak, M., \& Berns, G. S. (2018) Jealousy in dogs? Evidence from brain imaging. Animal Sentience 22(1)

Dalziel, D. J., Uthman, B. M., Mcgorray, S. P., \& Reep, R. L. (2003) Seizure-alert dogs: a review and preliminary study. Seizure, 12: 115-120

Denson, T. F. (2018) Inferring emotion from amygdala activation alone is problematic. Animal Sentience 22(9) 
Harmon-Jones, E., \& Harmon-Jones, S. K. (2018) On jealousy, envy, sex differences and temperament in humans and dogs. Animal Sentience 22(8)

Harris, C., \& Prouvost, C. (2014) Jealousy in dogs. PLoS ONE, 9(7): e94597

Kaminski, J., Nitzschner, M., Wobber, V., Tennie, C., Bräuer, J., Call, J., \& Tomasello, M. (2011) Do dogs distinguish rational from irrational acts? Animal Behaviour, 81: 195-203

Kaminski, J., Schulz, L., \& Tomasello, M. (2012) How dogs know when communication is intended for them. Developmental Science, 15: 222-232

Kujala, M. V. (2017) Canine emotions as seen through human social cognition. Animal Sentience 14(1)

Lim, K., Wilcox, A., Fisher, M., \& Burns-Cox, C. I. (1992) Type 1 diabetes and their pets. Diabetic Medicine, 9: S3-S4

Macpherson, K., \& Roberts, W. A. (2006) Do dogs (Canis familiaris) seek help in an emergency? Journal of Comparative Psychology, 120: 113-119

Marshall-Pescini, S., Ceretta, M., \& Prato-Previde, E. (2014) Do domestic dogs understand human actions as goal-directed? PLOS ONE, 9(9): e106530

Merola, I., Prato-Previde, E., \& Marshall-Pescini, S. (2011) Social referencing in dog-owner dyads? Animal Cognition, 15: 175-185

Merola, I., Prato-Previde, E., \& Marshall-Pescini, S. (2012) Dogs' social referencing towards owners and strangers. PLOS ONE, 7(10): e47653

Nitzschner, M., Melis, A., Kaminski J., \& Tomasello, M. (2012) Dogs (Canis familiaris) evaluate humans on the basis of direct experiences only. PLOS ONE, 7(10): e468804

Petter, M., Musolino, E., Roberts, W. A., \& Cole, M. (2009) Can dogs (Canis familiaris) detect human deception? Behavioural Processes, 82: 109-118

Prato-Previde, E., Nicotra, V., Pelosi, A., \& Valsecchi, P. (2018) Pet dogs' behavior when the owner and an unfamiliar person attend to a faux rival. PLOS ONE, 13(4): e0194577

Range, F., Horn, L., Viranyi, Z., \& Huber, L. (2009) The absence of reward induces inequity aversion in dogs. Proceedings of the National Academy of Sciences, 106: 340-345.

Serpell, J. A. (2018) Jealousy? Or just hostility toward other dogs? The risks of jumping to conclusions. Animal Sentience 22(13)

Silver, Z. A., \& Santos, L. R. (2018) Understanding dogs' neural responses in a food-giving paradigm. Animal Sentience 22(15)

Singer, P. (2018) Finding the green-eyed monster in the brain of a dog. Animal Sentience 22(3)

Tangney, J. P., \& Salovey, P. (1999) Problematic social emotions: Shame, guilt, jealousy, and envy. In Kowalski, R. M., \& Leary, M. R. (Eds.), The social psychology of emotional and behavioral problems: Interfaces of social and clinical psychology. American Psychological.

Vonk, J. (2018) Researchers, not dogs, lack control in an experiment on jealousy. Animal Sentience 22(2)

Walsh, C. J. (2018) Lessons from behaviour for brain imaging. Animal Sentience 22(7)

Zentall, T. R. (2018) Jealousy, competition, or a contextual cue for reward?. Animal Sentience 22(4) 